\title{
Mariano Picón-Salas
}

\section{Hagiografia}

(19:2) EATAS. mendigos y hechiceras. Quiero pintar ahora las figuras simples o grotescas de $\mathrm{mi}$ antigua hagiografia infantil: los seres que me hicieron reir o pensar en las historias que se cuentan de los santos, y pasaron delante de mi caracterizados y distintos, como las máscaras en un carnaval.

Pero en esto como luego lo veréis, también hay tragedia. En Rosario, la Iluminada, que presentia las muertes y las desgracias, en el inesperado fin de Vicentico, El Apóslol, y de la Negra Osa.

\section{ROSARIO, LA ILUMINADA}

De Rosario, la Iluminada, oi decir un dia al abuelo que nunca había conocido hombre. Esto era en labios de una persona como el abuclo tan apegado a las realidades, la mayor alabanza de la virtud.

Gozaba de mucho crédito y consideración en la casa desde que un dia, cuando la revolución del 99. habia anunciado la muerte de mi tio Benjamin, en el preciso momento en que éste caía herido de un balazo en el pecho, en la batalla de San Pedro de los Guamos.

La familia se habia refugiado entonces en la hacienda del Palotal para poner en guarda sus cosechas y animales de las bandas de forajidos que bajo el nombre simulado de ccomisio- 
nes: del Gobierno o de la Revolución, recorrian los campos atraillando las reses y caballos que conseguian y saqueando los graneros. Mi abuelo con su pandilla de peones armados de máuseres y machetes defendía su finca, y la gran casa de la hacienda era como un castillo feudal a donde acudian los conuqueros pobres de las inmediaciones a esconder sus pequeñas cosechas de trigo o de maiz. Con la impetuosidad de sus veinticinco años, el tío Benjamín militaba en la revolución, y cada tanto tiempo llegaba hasta la casa un spropio, venido del llano o de la cordillera, después de ocho o diez dias de marcha. trayendo la noticia de un nuevo triunfo liberal.

Aquel dia se asaba en el patio de la hacienda una ternera: se les convidaba a los peones, se vaciaban unas cuantas damajuanas de aguardiente de caña, y mi abuelo disparaba al aire una docena de veces su seguro winchester.

Esto hacian los hombres: las mujeres entretanto refugiadas en los patios interiores de la casa rezaban una novena. la de San Expedito o Santa Brígida, abogados en las grandes tribulaciones, o preparaban en la gran cocina de campana las salazones de chivo o de cordero para los tiempos de escasez. Cuando llega la estación lluviosa y se interrumpen las comunicaciones y se derrumban los caminos y caen los puentes, y la hacienda parece una isla inaccesible, en medio del rio desbordado y azotada por la lluvia y la tempestad.

Para que acompañara a las sniñas,-las niñas eran mis tias-habian llevado de la ciudad a Rosario, la Iluminada. Educada en el Convento de las Clarisas no se habia hecho religiosa porque en la época de tomar el velo le asaltaron no sé qué escrúpulos de conciencia, pero aprendió con las monjas todas esas artes sutiles que se aprenden en los viejos conventos, lejos del mundo: los finos bordados de hilo y de seda que llevan los paños de altar. los allajores y las tortas que le gustan al señor Obispo, el rosario de quince casas y la radiante oración del Magnificat: ^Magnifica mi alma al Señor y mi espiritu se regocija en Dios, mi Salvador, porque puso sus ojos en la humildad de su sierva, 
En la hacienda cumplia su apostolado sencillo quemando palma bendita $y$, rezando el trisagio en las noches de tempestad. repartiendo la comida de los peones. llevando la divina palabra a las almas loscas y oscuras de los campesinos. Averiguaba quienes entre los colonos vivian en concubinato y se ofrecia para coser las camisas del hombre y los vestidos de la mujer, si éstos se casaban. Era amiga del párroco de la aldea más próxima: lo habia ganado para su causa con varias fuentes de ssuspiross, y conseguia con él que eximiera a los contrayentes del pago de los derechos nupciales. Los Domingos reunia en uno de los patios de la casa a loda la chiquillería zaparrastrosa de la hacienda: les enseñaba el calecismo en el librito del Padre Ripalda, y era curioso oir a los muchachos que le respondian al pie de la letra y como si hablaran con el sacerdote imaginario del Catecismo:

-Decidme, niños, ¿sois crislianos?

- Si, padre, por la gracia de Dios.

- ¿Qué cosa es envidia?

-Es, padre, la tristeza del bien ajeno.

El buen abuelo volleriano la dejaba hacer: apenas alguna vez le dirigia una broma gruesa que ella esquivaba sonriendo; para el abuelo, que en su lucha con los hombres y la naturaleza poseía el secreto del mundo. Rosario era tan buena que nunca habia conocido hombre.

Y en esa cruda definición había más justicia. más alabanza. mayor experiencia de la vida que en otros abstraclos términos de hipócrita virtud.

Esto lo oi conlar en mi infancia.

Ocurrió que mientras ella rezaba en su habitación. llena de imágenes, por los que estaban en la guerra y por el tio Benjamin, la esperanza de la casa, oyó una voz quebrada y dolorida: la voz del tio Benjamin que pedia agua como devorado por una sed ardiente. 
Y no supo si soñó, o su imaginación anduvo por entre un campo de cadáveres, y alli le vió tendido en tierra, manando sangre por una gran herida abierta en el pecho.

Dudó en comunicar la visión, cuyo secreto sofocaba su alma sencilla, y lo dijo al abuelo que se burlaba de los presentimientos: para el abuelo. lio Benjamin era de hierro y nada podian contra él los picaros godos: pero días después un mensajero venido del propio campo de San Pedro de los Guamos trajo una carta enlutada: el abuelo no disparó su winchester como lo hacia cuando le anunciaban un triunfo de su causa, sino ordenó ensillar los caballos que había en la pesebrera. llamó a su mujer y sus hijas y sin decirles nada. las obligó a subir a las cabalgaduras.

Al abuelo no se le preguntaba ni se le discutia.

Ya en la ciudad, y como si hubiera ocurrido hacia mucho ticmpo. les dió la noticia.

-No griten, mujeres, que para algo debe servirles la religión. En cuanto a mi he dejado la hacienda abandonada a merced de los que quieran robarla, porque desde que falla él nada me interesa.

Desde entonces Rosario, la Iluminada. gozó de mucha consideración en la casa. Ya el abuelo ensombrecido y hecho más silencioso, no la importunó con sus gruesas bromas.

Devola de San Pascual Bailón, al favor de San Pascual ella atribuia sus presentimientos misteriosos de las muertes y las desgracias que iban a ocurrir en la familia.

Cuando alguien iba a morir, San Pascual tocaba tres veces en su habitación, en la noche, tres toques inconfundibles. Y le venía entonces el recuerdo de alguno que estaba próximo o lejano: se presentaba a la casa a averiguar por la salud de un pariente olvidado. de quien hacía mucho tiempo no se tenian noticias. Alguna vez coincidió su visita con el recibo de una carta o un telegrama que no se esperaban. 
En cierta ocasión le preguntó el abuclo:

- ¿Y ese santo desocupado. todavia no le pronostica mi muerte?

- Aún nada me ha dicho San Pascual, don Pedro, pero su cuenta es larga y seria bueno que ya se confesara.

$\mathrm{Y}$ el abuelo a quien las desgracias hicieron dócil, que no creía en nada, pero que contra nada se atrevia ya a luchar, mandó llamar a un vicjo cura amigo y liberal. Bebieron juntos en el escrilorio del abuelo varias copas de vino: recordaron su causa politica entonces vencida y sin esperanza; hablaron del liempo pasado y de la muerle que se acerca y se despidieron después de dos horas con el abrazo cordial de dos camaradas.

La abuela y las tías cargaron al haber de santidad de Rosario, la confesión del abuelo.

San Pascual-fiel amigo-no podia menos que anunciar a Rosario, la Iluminada, su propia muerte. Una tarde llegó a despedirse de la abuela y las tias y a darles las gracias. sonriendo, por toda la caridad que le hicieron. Se le inviló a merendar y contó que San Pascual tocaba ahora a su puerta todas las noches. Pero ella estaba tranquila: habia hecho confesión general y no se desprendia del cordón del Carmen.

Cuando se despidió le dijo a la abuela:

- Hasta la otra vida, doña Lucía.

La abuela le respondió que volviera a merendar muy pronto.

Pero una semana después entre los estandarles de tres cofradias-el blanco de San Pascual, el rojo de San Miguel Arcángel. el violeta de la Cofradia del Carmen-llevaron al Cementerio a Rosario, la Iluminada.

El abuelo repitió por una vez más su clásico y castizo elogio:-Era tan buena que no habia conocido hombre.

\section{VICENTICO}

Vicentico era el undécimo entre los apósloles a quienes el señor Obispo lavaba los pies en la ceremonia del Jueves Santo. Otros principes de la Iglesia para celebrar este acto evangélico 
del lavatorio, elegian doce niños de la buena y rica sociedad que llegaban muy limpios y paquetes y perfumados por sus mamás y cuyos rosados piececitos no desmerecian en la gran jofaina de oro, pero este señor Obispo tenía de su misión un concepto más rigido: pensaba que Cristo no buscó sus doce discípulos entre los niños de la aristocracia sino entre hombres humildes y maduros, ya heridos por el dolor de vivir, cuya única riqueza era la de sus vestidos rasgados y la del cielo azul de Judea. Y a pesar de las protestas del Deán y Cabildo que argumentaban que no habia tradición para el lavalorio de un Jueves Santo. este Obispo sencillo entró a la Catedral conduciendo sus doce apóstoles: doce pordioseros, doce pobres hombres ridiculos conocidos en la ciudad por las máscaras de sus caras, sus defectos físicos. los cómicos apodos con que los designaban los muchachos. Para que se presentaran dignamente a la ceremonia el señor Obispo les había costeado el valor de un baño caliente, un traje pobre pero limpio, y las más vistosas alpargatas que usaran jamás. El cristiano simbolismo del señor Obispo comparaba estas alpargatas con las evangélicas sandalias de Pedro y de Andrés.

Desde entonces slos apóstoles, formaron una verdadera institución en la ciudad. Estos hombres desamparados que iban de casa en casa pidiendo la limosna. descubrieron un motivo noble para vivir: ya les habia besado sus pies el señor Obispo y cada uno de ellos representaba a uno de los discipulos de Cristo. Como en toda congregación humana predominan los más fuertes, el Decanato de la sociedad y el imperioso papel de San pedro lo había fomado para si un mendigo apodado .El Tigres. por su cara manchada como la piel de un felino y porque defendia sus prerrogativas con un nudoso baslón.

Pero ya cuando los muchachos en calles y plazas le gritaban: ¡El Tigrel, como poseido de su papel superior no hacía caso: sonreía desdeñosamente y miraba de alto a bajo como si hablaran de otra persona. Ahora se llamaba San Pedro. 
Vicentico, pequeño como un enano, con unos ojos diminutos. movibles y risueños de ardilla, un bigote que parecia pegado con goma sobre la boca para hacer reir, representaba a uno de esos apóstoles mansos, todo humildad y cspontánea ternura, como San Juan. Él no discutia prerrogativas y estaba satisfecho con su undécimo lugar que graciosamente le había acordado el señor Obispo. Obedecia a San Pedro en cuanto las órdenes de San Pedro no eran arbitrarias porque éste se embriagaba algunas veces y queria atropellar la congregación. Pero Vicentico apenas tenia ánimos para protestar: sólo en casa de algunas de las señoras a donde iba a pedir limosna solía explayarse y contar los desmanes de San Pedro, que, ihorror de horrores!. con el dinero y la comida que le daban en las casas cristianas. mantenia una concubina. La coja Inés, una mendiga alta y flaca que engañaba con su cara pálida de anémica. su pañolón verdoso anudado al cuello y su voz lastimera de persona inocente. Mas en un momento de peligro en que fuera preciso tener una discusión con el Decano, hubiera salvado a Vicentico su cuerpo pequeño, su facilidad para escabullirse y su zalamera e irresistible corlesía. A veces los otros mendigos jugaban con él: lo levantaban en peso y lo peloteaban en el aire y él se dejaba hacer muy complacido.

Por lo demás gozaba de un privilegio que envidiaban sus compañeros: mientras éstos vivian en las afueras de la ciudad. en ranchos horribles o entre la algarabia de las casas de vecindad, el señor Obispo había acordado a Vicentico el permiso de vivir en el último piso del campanario. en un cuartucho desde cuyo alto agujero los seres y las cosas se veian pequeñitos. $\mathrm{Y}$ Vicentico, provisto de una intuitiva ironia, gustaba de asomarse a su torre algunas tardes, cuando bajo los pórticos de la Catedral los mendigos esperan a los señores Canónigos que salen de los ejercicios del Coro y que siempre les hacen merced... 
Asi viviendo en el campanario. Vicentico servia de ayudante ad-honorem al campanero: le ayudaba a locar los dobles y las visperas, $y$ en pascuas y aguinaldos-por dormir poco y tener lan próximas las campanas-despertaba a la ciudad con estrepitosos repiques en alta madrugada.

Fuera de estos cuidados, su principal preocupación durante todo el año era prepararse decorosamente para aquel gran día del Jueves Sanlo en que cerca del presbiterio. seguido de tres acólitos que le llevaban una jarra y una jofaina de oro y un paño de fina seda. Su Ilustrisima le lavaba y besaba los pies. ¡Cómo pintar el místico anonadamiento que le producía aquel beso y la suavisima fricción del paño de seda sobre su dura piel y la salida triunfal de los doce apóstoles, de a dos en fila, por la puerta ancha de la Catedral, después de concluida la ceremonial

Su Ilustrima les invitaba a almorzar aquel dia en el Palacio. les servian una mesa que simbolizaba la mesa de la Cena y ellos que individualmente se llamaban „El Tigre, Vicentico, èl cabeza chata, aquel dia eran San Pedro. San Andrés. San Juan. En la ciudad todos señalaban a los apóstoles. No necesitaban pedir limosna aquel dia porque espontáneamente todos les daban.

Favorecido con la ropavejería de las ricas casas. Vicentico guardaba para entonces un chaqué del año 98. una corbata de plastrón de esas que necesitaban todo un juego de cerrajería de resortes y hebillas para colocarse y un chaleco de seda que luciera en un baile un romántico doncel veinte años antes. En su tenida podría emprenderse un estudio comparativo de la historia y la geografia de las modas.

Jueves Santo.

El señor Obispo fué más pródigo que otros años, y les ofreció un nada evangélico almuerzo rociado con abundante vino.

El Prelado miraba comer a sus crialuras que, olvidadas del papel que representaban. la emprendian contra las viandas como si quisieran compensarse de doce meses de hambre. 
Quien bebia y comia más era San Pedro, por otro nombre El Tigre, que como Príncipe de los Apóstoles disponia a su leal arbitrio de una jarra de rojo vino.

El Tigre tenía motivos para querellarse con Vicentico porque corrian para él tiempos malos: se habia presentado a la festividad más andrajoso que los of́ros, porque el púdico Vicentico habia divulgado en las casas cristianas su concubinato con la Coja. y ahora a donde iba, a más de negarle la limosna, le imponían una lección de moral. Se permitian instruirle a êl, el Decano, de los deberes de los apóstoles. Le oponian como ejemplo a ese insignificante Vicentico.

Vicentico entretanto lucía chaqué, chaleco de seda, corbata de plastrón y Idesafio inaudito! hasta una cadena de niquel atravesada sobre un bolsillo del chaleco.

Ya en la mesa. El Tigre aludió con la autoridad de sus años. de su porte y de su investidura a ciertos hipócritas que hablando bajilo van a las casas a malponer a sus compañeros para ganar la limosna que se destina a éstos. ¡Cómo si cada quien no tuviera la responsabilidad de sus propios pecados!

Pero como terminara el almuerzo y se excitaran demasiado. un acólito del Obispo los conminó a irse para que no turbaran la santidad del Palacio.

Salieron a la calle: cada uno de los apóstoles tomó un camino distinto y esta era là oportunidad que acechaba El Tigre para acercarse a Vicentico.

La calle estaba desierta y apenas sobre la acera proyectaba la catedral la sombra de sus puertas entornadas por el duelo de la Iglesia, y se oía a lo lejos el ronco son de una matraca.

Era en ese momento la agonía de Cristo.

Vicentico quiso irse e insinuó como despedida una de esas sonrisas y corlesias con que evadiera el peligro otras veces:

- Hasta luego, hermano, y que le hagan mucha merced.

Pero ya El Tigre estaba alerta con sus ojos rojos de vino y envidia:

-IIntrigante, chismoso, a ver si ahora me las pagas todas! -y se le abalanzó al cuello inmovilizándolo. 
Brillaban ante los ojos de El Tigre como prendas de culpabilidad la gran corbata de plastrón y la cadena de niquel de Vicentico.

¿Qué esperaba de la vida, tan absurda para él, con su cara manchada, su miseria y el amor de La Coja, aquella mujer repugnante?

Entre los pliegues de la camisa llevaba escondida una navaja.

Y sin pensar, rápido, como si la enterrara en su vida absurda. la clavó en el inerme cuerpo de Vicentico.

Vicentico cayó de espaldas hecho una sola pelola sanguinolenta. Su corbata era ahora de púrpura y el viejo chaleco de seda lleno de salpicaduras simulaba un fabuloso chaleco de Canlasia.

Desde entonces se disolvió la Congregación de los Apóstoles: en la ceremonia del lavalorio. doce niñitos de la buena sociedad, limpios y perfumados, representaron a los discipulos de Cristo.

\section{LA NEGRA OSA, MUJER DEL INGLÉS}

Habia caido entre aquellas gentes candorosas de la sierra que no han visto nunca el mar. ni la agitación de los puertos ni la malicia de las grandes ciudades, como. una mensajera del misterio sabiendo leer el destino en las cartas de la baraja y conjurar los aojos y sortilegios que hacen las malas personas.

Esto abría para ella las huchas de aquellos montañeses sórdidos que le pedian talismanes para que a los niños salieran los dientes con lacilidad, o brevajes hechos de yerbas que sólo ella conocia, que había que cortar en el campo bajo la luna menguante para que adquirieran virlud mágica. Médica, bruja, hechicera, todo era en el pueblo la Negra Osa.

La apodaban asi por semejarse en su corpulencia. su rostro de mulata, su pelo desgreñado y las grandes ajorcas tintineantes que llevaba en los brazos, con la osa negra que Maese Nicola, el italiano, exhibia y hacia danzar en la plaza pública. 
Pero tenía su leyenda, cosa que entre aquellos montañeses sin imaginación y sin aventura se aprecia entre todo. Decian que en su juventud, en un puerto de la costa, se habia enamorado de ella y la habia hecho su amante uno de eslos ingleses que en las ciudades tropicales sienten la atracción exótica, tan picante y tan viva como la de las especias de Oriente para los navegantes del siglo XVI. de las mulatas de ojos negros y encendidos cuyos cuerpos fuertes y obscuros. la boca grande y carnosa como la corleza de un higo y el pelo áspero. abundante y lustroso, invila a los hombres rubios como un viaje a un pais bárbaro donde imperaran la elerna desnudez y el calor eterno. Pero agotan el clima y el amor de las mulatas a estos hombres flemáticos: nunca pueden civilizarlas porque ellas siempre se escapan como animales monteses; el pobre ingles pagará su curiosidad con una mujer indócil que nunca aprende el confort y el orden de la casa y que en los momentos más serios-aquellos que un inglés no puede considerar sino muy en serio-aparece saltando como una cabra salvaje y riendo, riendo tanto hasla mostrar toda la dentadura. Esas denladuras blancas, parejas y firmes y maravillosas de las negras.

De la aventura con el inglés, que su fealdad de ahora hacia considerar inverosimil, quedábanle a la Negra Osa algunas de esas sorlijas de piedras rojas o azules que aprecian tanto las mulatas y aquella cantinela, aquel tifulo de orgullo que sacaba a relucir en todas las conversaciones:

- Cuando mi esposo, el inglés...

Estas historias y su cabalistica sabiduria franqueábanle las puerlas de lodas las casas del pueblo. Los curas no la miraban bien porque les hacia la competencia propagando otros procedimientos distintos de la devoción y las ofrendas a los santos. para ganarse la volunlad de las fuerzas invisibles. Y las monedas que no caian en la alcancia de la Virgen del Socorro o San Expedilo, iban directas a los bolsillos de la Negra Osa.

Pero icómo se daban por bien servidas las muchachas del pueblo, las que languidecen de soledad y fastidio en aquellos 
sombrios caserones provincianos, cuando ella, sacando del seno la mugrienta baraja española, les vaticinaba el destinol

Tomaba en las suyas las manos de la recatada doncella: miraba fijamente con sus grandes ojos de mulata las lineas torcidas y pequeñilas que iban de la palma a la muñeca, quedäbase absorta como descifrando los jeroglíficos que alli se le ofrecian, y luego con voz melosa, con el tartamudeo de quien recibe el misterio a pequeñas dosis, decia a la cuitada:

- Miro en tu mano, cara bonita. la linea de un próximo sufrimiento amoroso. Pero todo concluirá bien: es caballero ríco y Tormal, montará casa y con el tiempo hasta le llevará a pasear por tierras extranjeras. Acaso sea rubio e inglés como mi difunto.

Otras veces el naipe, la carta que la interesada eligió entre un montón, servia de oráculo, y el as de oro anunciaba las rabulosas herencias de los parientes que viven lejos, las copas alguna fiesta, el caballo de bastos un largo viaje por tierra, y cuando salía el as de espadas eran de mirar las muecas y visajes de la adivina:

-No permita el cielo que se cumplan los prónósticos, porque veo luto en esta casa. El as de espadas está manchado de sangre y se suspende sobre la cabeza de alguno. Yo rezeré porque tal no suceda. Y ahora, Cara Bonita, esloy débil y me vienen los flatos y auxiliáme con lo que puedas.

Y Cara Bonita va a buscarle harina o azúcar, algunas monedas o un traje usado de vivos colores, de los que aprecia tanto la Negra Osa.

Tiene ésta fama de avara: dicen que entierra el dinero que recoge y que guarda todavia tesoros irobados al inglés. ICómo se expande la imaginación provinciana hablando de estos tesoros del inglés!

Y la-casa de la Negra Osa contribuye a avivar el misterio: vive en despoblado, en una choza cerca del río, donde en la noche se oyen exíraños ruidos. 
Para su imprevisto matrimonio con Pedro estuvo buscando auxilios entre las gentes del pueblo la Negra Osa. Y todos. por lo pintoresco de la aventura, porque les dió motivo para reir varias semanas, le dieron dinero o ropas. El matrimonio lué un espectáculo más divertido que las funciones de circo y que los palos engrasados y las cucañas con que se celebran en el pueblo las fiestas patronales. Asi dicen que en la ceremonia no faltó a ella ningún detalle decorativo: ni el velo blanco, ni la corona de azahar. Repartia sonrisas a diestra y siniestra, y embriagada de gozo y orgullo no reparó cuando un grupo de muchachos de la calle le gritaron el apodo fatidico: INegra Osal Pedro iba a su lado con la cara tristemente resignada de uno que condujeran a la horca.

Pedro habia sido sirviente en un Convento: tenia lama de correcto y honesto como todo lo que sale de aquellas casas, y ahora, deseoso de adquirir una sifuación más holgada. hacia de buhonero. y con su cajón de sorpresas-lodo a cuarenta centavos-recorría en excursiones de una a dos semanas hasta los más apartados campos y aldeas de la provincia.

Como si fuera preciso explicar tan desproporcionado connubio. la Negra Osa decia en sus visitas a las casas:

-El pobre muchacho empieza a trabajar y necesita de alguien que se duela de él. Que le tenga la ropita de muda remendada y limpia cuando regresa hecho girones, de sus viajes. Además cuenta para aumentar su negócito con los pequeños ahorros que yo pueda darle. Pero yo no le entregaré todo porque a pesar de ser muy buen muchacho, hay por esos campos y pueblos mujeres malas que hechizan a los jövenes para sacarles el dinero. ¿Quién libra de tentaciones a la juventud?

$\mathrm{Y}$ como una madre que no hubiera perdido el ardor de la esposa, asi fué ella para Pedro. Todos en el pueblo nolaron la transformación de la Negra Osa que ahora iba a la Iglesia y negábase a interpretar el destino. 
- Cosas de espiritus que diz están prohibidas-contestaba a quienes se lo requerian.

El pueblo tuvo una bruja y una hechicera menos porque la $\mathrm{Ne}$ gra Osa se dedicaba ahora a vender frituras en el mercado, y las alcancias de la Virgen del Socorro y San Expedito se colmaban de nuevo con las ofrendas metálicas de los devotos.

Estaban satisfechos los señores curas.

Habian vuelto la religión y la piedad a aquel pueblo dejado tanto tiempo por la mano de Dios.

Coincidió con uno de los viajes que Pedro hacia a los campos a vender su quincalla.

pero no era posible dudar de Pedro.

Cuando la encontraron inmóvil en su camastro tendria por lo menos dos dias de estar abandonada alli.

El estómago se inflaba monstruoso hasta levantar las ropas, la cara habia quedado fijada en una horrible contorsión final y sobre los labios se acumulaba una saliva verduzca.

Negra y desmelenada, parecia una fiera que el cazador matara en el bosque. Nunca le convino mejor su apodo de Negra Osa.

Dijeron que habia sido envenenada y como si el móvil del crimen fuera el robo, en la habitación se veían ladrillos removidos y agujeros en la pared.

No se halló nada de dinero.

En un viejo baúl claveteado encontraron objetos que supusieron de brujeria: pelos y cerda de animales, haces de yerbas, huesos y un frasco de un aceite espeso y hediondo. Un perito opinó que era aceite de tortuga.

De Pedro, el buhonero, no se supo más. 